\title{
Updates on Prevention of Cardioembolic Strokes
}

\author{
Mehmet Akif Topcuoglu, ${ }^{\mathrm{a}}$ Liping Liu, ${ }^{\mathrm{b}}$ Dong-Eog Kim, ${ }^{\mathrm{c}}$ M. Edip Gurol ${ }^{\mathrm{d}}$ \\ aDepartment of Neurology, Hacettepe University, Ankara, Turkey \\ ${ }^{b}$ Department of Neurology, Beijing Tiantan Hospital, Capital Medical University, Beijing, China \\ 'Department of Neurology, Dongguk University Ilsan Hospital, Dongguk University College of Medicine, Goyang, Korea \\ ${ }^{d}$ Department of Neurology, Massachusetts General Hospital, Harvard Medical School, Boston, MA, USA
}

Cardiac embolism continues to be a leading etiology of ischemic strokes worldwide. Although pathologies that result in cardioembolism have not changed over the past decade, there have been significant advances in the treatment and stroke prevention methods for these conditions. Atrial fibrillation remains the prototypical cause of cardioembolic strokes. The availability of new long-term monitoring devices for atrial fibrillation detection such as insertable cardiac monitors has allowed accurate detection of this leading cause of cardioembolism. The non-vitamin K antagonist oral anticoagulants have improved our ability to prevent strokes for many patients with non-valvular atrial fibrillation (NVAF). Advances in left atrial appendage closure and the U.S. Food and Drug Administration approval of the WATCHMAN (Boston Scientific) device for stroke prevention in NVAF patients who have an appropriate rationale for a nonpharmacological alternative, have revolutionized the field and provided a viable option for patients at higher hemorrhagic risk. The role of patent foramen ovale closure for secondary prevention in selected patients experiencing cryptogenic ischemic strokes at a relatively young age has become clearer thanks to the very recent publication of long-term outcomes from three major studies. Advances in the management of infective endocarditis, heart failure, valvular diseases, and coronary artery disease have significantly changed the management of such patients, but have also revealed new concerns related to assessment of ischemic versus hemorrhagic risk in the setting of antithrombotic use. The current review article aims to discuss these advances especially as they pertain to the stroke neurology practice.

Keywords Ischemic stroke; Cardioembolism; Atrial fibrillation; Anticoagulants; Left atrial appendage closure; Patent foramen ovale closure

\author{
Correspondence: M. Edip Gurol \\ Department of Neurology, \\ Massachusetts General Hospital, \\ Hemorrhagic Stroke Research Program, \\ 175 Cambridge Street, Suite 300, \\ Boston, MA 02114, USA \\ Tel: +1-617-726-8459 \\ Fax: +1-506-700-2420 \\ E-mail:edip@mail.harvard.edu \\ Received: March 13, 2018 \\ Revised: May 16, 2018 \\ Accepted: May 23, 2018
}

\section{Introduction}

Cardiac embolism (CE) is a leading etiology of ischemic strokes, the cause of $25 \%$ to $40 \%$ of cerebral infarctions worldwide. Cardioembolic strokes are associated with poor outcomes and relatively high recurrence rates compared to other ischemic stroke causes. The major causes of CE have not changed over the past decade, but significant advances in their primary treatment and stroke prevention methods have been achieved.
Atrial fibrillation (AF) remains the prototypical cause of CE. External prolonged monitoring methods have allowed better detection of paroxysmal AF, and more recently, insertable cardiac monitors (ICMs) have improved accurate detection of even brief AF episodes for up to 3 years. ${ }^{1}$ Although not so novel, the nonvitamin $\mathrm{K}$ antagonist oral anticoagulants (NOAC) have improved stroke prevention in patients with non-valvular atrial fibrillation (NVAF). ${ }^{1,2}$ The role of the left atrial appendage (LAA) in NVAF-related CE has become clearer and there have been 
major advances in left atrial appendage closure (LAAC) resulting in the recent U.S. Food and Drug Administration (FDA) approval of the WATCHMAN (Boston Scientific, Marlborough, MA, USA) device for stroke prevention in patients with appropriate rationale for nonpharmacological alternatives. ${ }^{3}$ Recent publication of long-term follow up of patent foramen ovale (PFO) closure trials have changed the landscape in that field resulting in FDA approval of this approach for secondary stroke prevention..$^{4-6}$ Advances in the procedural management of infective endocarditis (IE), heart failure (HF), valvular disease, and coronary artery disease have resulted in improvements but have also revealed new concerns related to assessment of ischemic versus hemorrhagic risk in the setting of antithrombotic use.

One revolutionary advance has been a better understanding of the causes and risk of another and much more severe type of stroke-intracerebral hemorrhage (ICH). ICHs constitute onethird of all strokes worldwide and carry a high risk of death and severe disability., ${ }^{3,7}$ ral anticoagulants (OAC) including warfarin and NOACs are common causes of severe ICHs. Neuroimaging markers that can predict first-time or recurrent ICH risk have been validated. ${ }^{3}$ Neurologists who are familiar with both ischemic and hemorrhagic stroke management need to balance the risks and benefits of different medical and nonpharmacological CE prevention approaches in conjunction with the cardiologists and other medical specialists. The most relevant markers of $\mathrm{ICH}$ risk are discussed in a separate paper on prevention of lacunar and hemorrhagic strokes published in this same issue of the Journal of Stroke. ${ }^{8}$ The current article will review advances in CE stroke prevention emphasizing the aspects most relevant to the practicing neurologists and stroke specialists.

\section{Updates on stroke prevention in atrial fibrillation}

$A F$, whether related to rheumatic valve disease or not, remains the most important cause of CE worldwide. ${ }^{9}$ The prevalence of AF increases with age and it is closely linked to vascular risk factors such as hypertension, diabetes mellitus, coronary artery disease, HF, thyroid dysfunction, sleep apnea, obesity, smoking, and alcohol consumption. ${ }^{1,10}$ About $2 \%$ of the population younger than 65 years, and $9 \%$ of people aged 65 years or older have AF in the United States. ${ }^{11}$ The presence of AF increases the risk of stroke by about 5-fold in all age groups. ${ }^{12}$ Warfarin remains the only approved medication for valvular AF; used with dose-adjustment based on target international normalized ratio (INR). Concurrent aspirin and warfarin use with INR targets of 2.5 to 3.5 is recommended for patients with mechanical heart valves, while warfarin alone with INR target of
2 to 3 is used for most other patients with AF. Embolic risk scores such as $\mathrm{CHADS}_{2} \mathrm{CHA}_{2} \mathrm{DS}_{2}$-VASc, and ATRIA provide estimates of the risk of ischemic strokes in NVAF with some limitations. ${ }^{1,13-15}$ Despite the tendency to overestimate embolic risk, $\mathrm{CHA}_{2} \mathrm{DS}_{2}$-VASc has become the most commonly used embolic risk score recommended by both European and American AF management guidelines. ${ }^{9,10,15,16}$

The cutoff score for using OACs in NVAF is $\geq 1$ per European guidelines and $\geq 2$ per the US guidelines; patients with a score of 1 can be managed with either OAC or antiplatelet per the latter. The United States guidelines also recommend a shared decision-making approach where the responsible clinician discusses the advantages (prevention of embolism and associated strokes) as well as potential risks (major hemorrhage) of OAC medications with the patient. The same guidelines also suggest periodic review and discussion of the changing risk/benefit profile of the preventive treatment over time. Examples to such changes might include: starting a patient with initially low $\mathrm{CHA}_{2} \mathrm{DS}_{2}$-VASc on anticoagulation when the risk increases with age or as a result of the appearance of a new risk factor; considering a patient on OAC for LAAC after sustaining ICH or manifesting any marker of high ICH risk such as brain microbleeds. A multidisciplinary approach that includes the cardiologist, neurologist and other specialists when needed, is helpful for optimal management of AF patients with complications such as hemorrhagic risk.

AF is also classified based on its temporal pattern as permanent, persistent, or paroxysmal. The paroxysmal category can be missed among inpatients even after an AF-related embolic stroke, and longer duration outpatient monitoring ( $\geq 72$ hours) is therefore recommended. It is important to correctly diagnose or rule out AF as both failure to take appropriate prevention measures and the unnecessary use of OAC have serious consequences-embolic stroke and $\mathrm{ICH}$ respectively. A recent major advance in the field was the development of ICMs that were shown to be superior to conventional strategies for detecting $\mathrm{AF}^{17}{ }^{17}$ ICMs can be implanted with a very low complication risk $(<1 \%)$ even as an outpatient and provide highly sensitive AF monitoring for 2 to 3 years (Figure 1). ${ }^{18}$ Other available outpatient monitoring strategies include Holter (24 to 72 hours), mobile cardiac outpatient telemetry devices (up to 4 weeks) and electrocardiographic patch devices (up to 4 weeks). ${ }^{1}$ These external devices have a relative advantage of ease of use and lower cost, but require patient compliance, have reduced sensitivity, and cannot be used for rhythm monitoring for longer than 2 to 4 weeks. The median time to detection of AF using ICM in a large randomized controlled trial (RCT) and the largest available observational cohort was 84 days (interquartile range 

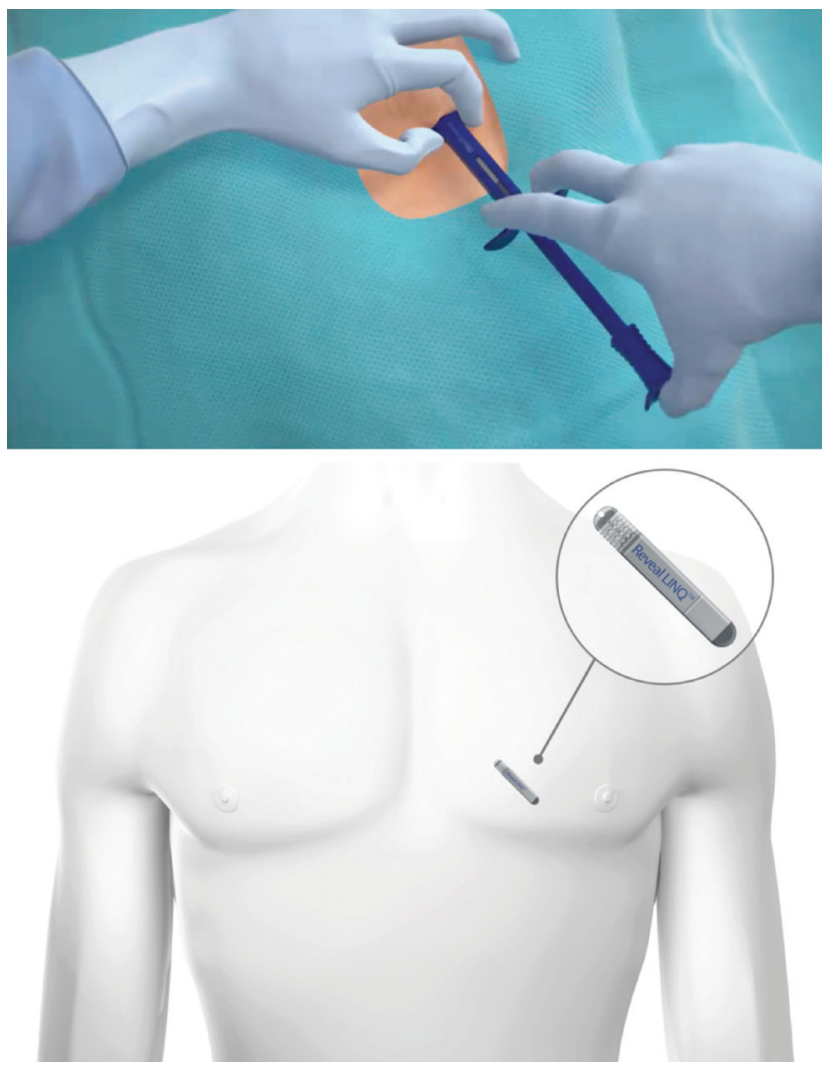

Figure 1. Placement of an insertable cardiac monitor. The insertable cardiac monitor is placed under the skin using an injection system through a simple incision. Reproduced with permission of Medtronic, Inc. (http:// www.medtronic.com).

[IQR], 18 to 265) and 112 days (IQR, 35 to 293), respectively. ${ }^{17,19}$ Long-term (2 to 3 years) monitoring with ICM is thus an attractive approach with high accuracy for AF detection, with minimal patient compliance. All ischemic stroke patients should receive at least one electrocardiogram (EKG) and should ideally be kept on telemetry during hospital stay. For patients with non-lacunar infarcts, long-term monitoring should be considered if no other clear stroke etiology is found. Starting all such patients on a NOAC without confirming the presence of AF does not prevent ischemic strokes better than aspirin alone and poses increased risk of brain hemorrhages by 4 to 6.5 folds. ${ }^{20}$ There is a growing body of literature on the minimum duration of AF before occurrence of embolic events but until we obtain data from properly designed RCTs, even a short duration (1 to 2 minutes) of unprovoked AF should trigger consideration of preventive measures especially in high risk patients such as ischemic stroke survivors.

Life-long OAC use is currently the norm for stroke prevention in patients with AF who are not at high risk of hemorrhage. Warfarin decreases stroke risk by $64 \%$ compared to placebo, and $47 \%$ compared to aspirin in NVAF. ${ }^{21}$ Warfarin also increas- es the risk of $\mathrm{ICH}$ by 5 folds compared to placebo and 2 folds compared to aspirin. ${ }^{22}$ In NVAF patients without past history or high risk for $\mathrm{ICH}$, warfarin is superior to placebo and aspirin for preventing all strokes but not vascular death or all cause deaths. Warfarin therefore has been the gold standard for stroke prevention in NVAF patients who do not have contraindications for long-term anticoagulation.

A direct thrombin inhibitor (dabigatran) and three factor Xa inhibitors (rivaroxaban, apixaban, edoxaban) collectively called NOACs have been approved for the same indication (Table 1). ${ }^{23-}$ ${ }^{27}$ These drugs are noninferior to warfarin for overall stroke

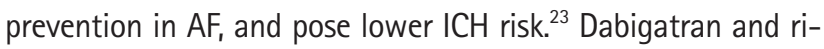
varoxaban however, have shown higher gastrointestinal hemorrhage risk. These NOACs have shown a trend for mortality benefit compared to warfarin. They have multiple other advantages including ease of use. Their effect starts within 1 to 2 hours after the first dose and they have less food/drug interactions than warfarin. They do not require blood draws as their effect is fairly predictable in patients without renal failure. Their effect wears off after 24 to 48 hours of the last dose, which could be an advantage in case of bleeding or if surgery is needed, but also potentially a disadvantage for risk of embolism in patients with poor compliance (even when 1 to 2 doses are missed). Another advantage is that they have been proven to have similar efficacy to warfarin in the presence of comorbidities not uncommonly seen with AF such as mild HF and history of cardioversion.

Idarucizumab is a humanized monoclonal antibody fragment that binds dabigatran, and is currently FDA-approved as a reversal agent for this direct thrombin inhibitor. ${ }^{28}$ Andexanet alfa, a modified recombinant derivative of factor $\mathrm{Xa}$, was recently approved by FDA as a candidate reversal agent for rivaroxaban and apixaban. ${ }^{29}$ The clinical studies of both Idarucizumab and andexanet alfa provided evidence for reversal of the laboratory findings associated with the respective NOACs. However, none of these studies were randomized and we do not have evidence for the clinical efficacy of these reversal agents. It is important to use available reversal agents for NOAC-related hemorrhages, but it is unlikely that these drugs will improve outcomes especially in ICHs that are already sizeable or at a critical brain location upon presentation.

Disadvantages of NOACs include higher risk of gastrointestinal side effects especially hemorrhage, safety concerns in older adults with renal failure, higher cost, and poor compliance as a result of these problems. The FDA has issued warnings against NOAC use in patients with mechanical valves as well as increased risk of thromboembolic events even in case of 1 to 2 missed doses. Recent real-world data also showed that more 
Table 1. Summary of non-vitamin K antagonist oral anticoagulant studies

\begin{tabular}{|c|c|c|c|c|c|}
\hline Study & Patients & NOAC & Comparison & Outcome & Conclusions for NOAC vs. warfarin \\
\hline $\begin{array}{l}\text { Connolly et al. }(2009)^{24} \\
\text { RE-LY trial }\end{array}$ & $\begin{array}{l}\text { NVAF, mean } \\
\mathrm{CHADS}_{2}=2.1, \text { no } \\
\text { prior } \mathrm{ICH}, \mathrm{CrCl} \\
\geq 30 \mathrm{~mL} / \mathrm{min}\end{array}$ & $\begin{array}{l}\text { Dabigatran } 150 \\
\text { mg twice daily } \\
(n=6,076)\end{array}$ & $\begin{array}{l}\text { Warfarin, target } \\
\text { INR=2-3, mean } \\
\text { TTR=64\% } \\
(\mathrm{n}=6,022)\end{array}$ & $\begin{array}{l}\text { Stroke, systemic embolism, } \\
\text { death, major bleeds (ICH, } \\
\text { GI) during } 2 \text { years of follow- } \\
\text { up }\end{array}$ & $\begin{array}{l}\text { Noninferior for stroke/embolism \& ma- } \\
\text { jor bleeds, lower ICH risk but higher } \\
\text { for GI bleeds, MI, GI upset with dabig- } \\
\text { atran, permanent discontinuation } \\
\text { (21.2\% vs. } 16.6 \%)\end{array}$ \\
\hline $\begin{array}{c}\text { Patel et al. }(2011)^{25} \\
\text { ROCKET AF trial }\end{array}$ & $\begin{array}{l}\mathrm{NVAF}_{1} \text { mean } \\
\mathrm{CHADS}_{2}=3.5, \text { no } \\
\text { prior ICH, } \mathrm{CrCl} \\
\geq 30 \mathrm{~mL} / \mathrm{min}\end{array}$ & $\begin{array}{l}\text { Rivaroxaban } 20 \\
\text { mg once daily } \\
(n=7,131)\end{array}$ & $\begin{array}{l}\text { Warfarin, target } \\
\text { INR=2-3, mean } \\
\prod R=55 \% \\
(n=7,133)\end{array}$ & $\begin{array}{l}\text { Stroke, systemic embolism, } \\
\text { death, major bleeds (ICH, } \\
\text { GI) during } 1.94 \text { years of fol- } \\
\text { low-up }\end{array}$ & $\begin{array}{l}\text { Noninferior for stroke/embolism \& ma- } \\
\text { jor bleeds, lower ICH risk but higher } \\
\text { for GI bleed with rivaroxaban, perma- } \\
\text { nent discontinuation ( } 23.7 \% \text { vs. } \\
22.2 \% \text { ) }\end{array}$ \\
\hline $\begin{array}{l}\text { Granger et al. }(2011)^{26} \\
\text { ARISTOTLE trial }\end{array}$ & $\begin{array}{l}\mathrm{NVAF}_{1} \text { mean } \\
\mathrm{CHADS}_{2}=2.1 \text {, no } \\
\text { prior ICH, } \mathrm{CrCl} \\
\geq 25 \mathrm{~mL} / \mathrm{min}\end{array}$ & $\begin{array}{l}\text { Apixaban } 5 \mathrm{mg} \\
\quad \text { twice daily } \\
(\mathrm{n}=9,120)\end{array}$ & $\begin{array}{l}\text { Warfarin, target } \\
\text { INR=2-3, mean } \\
\prod R=62 \% \\
(n=9,081)\end{array}$ & $\begin{array}{l}\text { Stroke, systemic embolism, } \\
\text { death, major bleeds (ICH, } \\
\text { GI) during } 1.8 \text { years of fol- } \\
\text { low-up }\end{array}$ & $\begin{array}{l}\text { Noninferior for stroke/embolism \& ma- } \\
\text { jor bleeds, lower ICH risk with apixa- } \\
\text { ban, permanent discontinuation } \\
\text { (25.3\% vs. } 27.5 \%)\end{array}$ \\
\hline 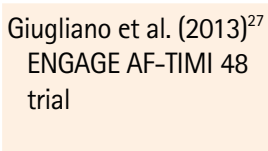 & $\begin{array}{l}\text { NVAF, mean } \\
\mathrm{CHADS}_{2}=2.8 \text {, no } \\
\text { prior } \mathrm{ICH}, \mathrm{CrCl} \\
\geq 30 \mathrm{~mL} / \mathrm{min}\end{array}$ & $\begin{array}{l}\text { Edoxaban } 60 \mathrm{mg} \\
\text { once daily } \\
(\mathrm{n}=7,035)\end{array}$ & $\begin{array}{l}\text { Warfarin, target } \\
\text { INR=2-3, mean } \\
\prod R=66 \% \\
(n=7,036)\end{array}$ & $\begin{array}{l}\text { Stroke, systemic embolism, } \\
\text { death, major bleeds (ICH, } \\
\text { GI) during } 2.8 \text { years of fol- } \\
\text { low-up }\end{array}$ & $\begin{array}{l}\text { Noninferior for stroke/embolism \& ma- } \\
\text { jor bleeds, lower ICH risk with edoxa- } \\
\text { ban, permanent discontinuation } \\
(34.4 \% \text { vs. } 34.5 \%)\end{array}$ \\
\hline
\end{tabular}

NOAC, non-vitamin K antagonist oral anticoagulant; RE-LY, The Randomized Evaluation of Long-Term Anticoagulation Therapy; NVAF, nonvalvular atrial fibrillation; $\mathrm{CHADS}_{2}$, congestive heart failure, hypertension, age $\geq 75$ years, diabetes mellitus, stroke (double weight); $\mathrm{CrCl}$, creatinine clearance; INR, international normalized ratio; TR, time in therapeutic range; ICH, intracranial hemorrhage; Gl, gastrointestinal; MI, myocardial infarction; ROCKET AF, The Rivaroxaban Once Daily Oral Direct Factor Xa Inhibition Compared with Vitamin K Antagonism for Prevention of Stroke and Embolism Trial in Atrial Fibrillation; ARISTOTLE, Apixaban for Reduction in Stroke and Other Thromboembolic Events in Atrial Fibrillation; ENGAGE AF-TIMI 48, The Effective Anticoagulation with Factor Xa Next Generation in Atrial Fibrillation-Thrombolysis in Myocardial Infarction 48 trial.

than half of patients receiving lower doses of NOACs, mostly for fear of side effects, did not have any indication for the lower dose. ${ }^{30}$ It is important to use the appropriate doses of these medications as the use of lower and higher doses are associated with elevated ischemic and hemorrhagic risks, respectively.

All OACs, including NOACs, significantly increase the risk of $\mathrm{ICH}$ and other major and minor bleeding risks. ${ }^{31}$ None of the phase 3 NOAC studies included patients with past history of ICH or known high bleeding risk, so the effects of NOACs on such patients are unknown. Even in survivors of embolic appearing cerebral infarct at low baseline ICH risk, NOAC use was associated with a 4- to 6.5-fold higher risk of brain hemorrhages compared to aspirin in a recently published RCT (NAVIGATE ESUS). ${ }^{20}$ It is also well-known that NOAC-related ICH have very high mortality and disability rates, similar to warfarin-related $\mathrm{ICH}^{3,16}$ It is therefore important to consider stroke prevention measures that do not rely on long-term anticoagulation in patients who have a higher hemorrhagic risk. Such patients include survivors of any type of $\mathrm{ICH}$, people having imaging markers of higher ICH risk such as microbleeds, cortical superficial siderosis, moderate-to-severe white matter disease, older adults with dementia or high risk of falling, and patients with past history of bleeding in a different organ system. The neurologic conditions that increase ICH risk are further detailed in another article from this issue and a recent review. ${ }^{3,8}$
LAA is known to be the site of thrombus in over $90 \%$ of NVAF patients with an embolic event. ${ }^{32}$ The complex morphological features of the LAA are a possible explanation for this. ${ }^{33}$ Several different methods have been developed to exclude LAA from left atrium, and therefore systemic circulation. These methods include pure endocardial closure (least invasive), hybrid endocardial and epicardial exclusion, and surgical obliteration (Table 2 and Figure 2). Only one endocardial approach, WATCHMAN device, has been studied in phase 3 RCTs against warfarin for clinical stroke prevention (Figure 2A). The first study, Watchman Left Atrial Appendage System for Embolic Protection in Patients with Atrial Fibrillation (PROTECT AF), showed both non-inferiority and superiority of this approach for overall stroke prevention as well as significant reductions in $\mathrm{ICH}$ and mortality when compared to the warfarin arm. ${ }^{34}$ The second RCT was not powered to demonstrate clinical benefit but its analysis failed to show noninferiority to warfarin despite similar numerical event numbers, mainly due to an unexpectedly low stroke rate in the warfarin arm. ${ }^{35}$ LAAC using WATCHMAN was approved by FDA for NVAF patients who need anticoagulation for stroke prevention and have an appropriate rationale to seek a nonpharmacological alternative to warfarin. ${ }^{3}$ These patients typically need OAC for 6 weeks after the procedure to prevent device thrombosis, followed by dual antiplatelets for another 4.5 months after which they are main- 
Table 2. Summary of left atrial appendage closure studies

\begin{tabular}{|c|c|c|c|c|c|}
\hline Study & Patients & Intervention & Comparison & Outcome & Conclusions for LAAC \\
\hline $\begin{array}{l}\text { Reddy et al. }(2014)^{34} \\
\text { PROTECT AF trial }\end{array}$ & $\begin{array}{l}\text { NVAF with mean } \\
\mathrm{CHADS}_{2}=2.2\end{array}$ & $\begin{array}{l}\text { LAA closure with } \\
\text { the WATCHMAN } \\
\text { device, antithrom- } \\
\text { botic protocol } \\
(n=463)\end{array}$ & $\begin{array}{l}\text { Warfarin, target } \\
\text { INR=2-3, mean } \\
\text { TTR=66\% }(n=244)\end{array}$ & $\begin{array}{l}\text { Stroke, systemic embolism, } \\
\text { death, major bleeds (ICH, } \\
\text { GI) during } 3.8 \text { years of fol- } \\
\text { low-up }\end{array}$ & $\begin{array}{l}\text { Noninferior for all stroke/embolism; su- } \\
\text { perior for mortality and ICH preven- } \\
\text { tion against warfarin }\end{array}$ \\
\hline $\begin{array}{l}\text { Holmes et al. }(2014)^{35} \\
\text { PREVAIL trial }\end{array}$ & $\begin{array}{l}\text { NVAF with mean } \\
\mathrm{CHADS}_{2}=2.6\end{array}$ & $\begin{array}{l}\text { LAA closure with } \\
\text { the WATCHMAN }{ }^{\circledast} \\
\text { device, antithrom- } \\
\text { botic protocol } \\
(n=269)\end{array}$ & $\begin{array}{l}\text { Warfarin, target } \\
\qquad \begin{array}{l}\text { INR }=2-3 \text {, mean } \\
T R=68 \%(n=138)\end{array}\end{array}$ & $\begin{array}{l}\text { Early/late (18 months) safety } \\
\text { and efficacy }\end{array}$ & $\begin{array}{l}\text { Improved procedural safety, noninferior } \\
\text { for prevention of ischemic stroke and } \\
\text { systemic embolism }>7 \text { days post-pro- } \\
\text { cedure against warfarin }\end{array}$ \\
\hline $\begin{array}{l}\text { Tzikas et al. }(2016)^{37} \\
\text { A retrospective obser- } \\
\text { vational study }\end{array}$ & $\begin{array}{l}\text { NVAF with mean } \\
\mathrm{CHADS}_{2}=2.8\end{array}$ & $\begin{array}{l}\text { LAA closure with } \\
\text { the AMPLATZER } \\
\text { Cardiac Plug, an- } \\
\text { tithrombotic pro- } \\
\text { tocol }(n=1,047)\end{array}$ & Not available & $\begin{array}{l}\text { Procedural safety and feasi- } \\
\text { bility, 13-month follow-up }\end{array}$ & $\begin{array}{l}\text { Successful implantation }(97.3 \%) \text {, cardi- } \\
\text { ac tamponade }(1.24 \%) \text {, procedure-re- } \\
\text { lated stroke }(0.86 \%) \text {, device emboliza- } \\
\text { tion }(0.77 \%) \text {, procedure-related } \\
\text { deaths }(0.76 \%) \text {, annual stroke rate } \\
(2.3 \%)\end{array}$ \\
\hline $\begin{array}{l}\text { Reddy et al. }(2017)^{36} \\
\text { A national clinical } \\
\text { registry study in the } \\
\text { U.S. }\end{array}$ & $\begin{array}{l}\text { NVAF, consecu- } \\
\text { tive WATCH- } \\
\text { MAN cases af- } \\
\text { ter FDA ap- } \\
\text { proval }\end{array}$ & $\begin{array}{l}\text { LAA closure with } \\
\text { the WATCHMAN }{ }^{\circledast} \\
\text { device, antithrom- } \\
\text { botic protocol } \\
(n=3,822)\end{array}$ & Not available & $\begin{array}{l}\text { Procedural performance and } \\
\text { complication rates within } 7 \\
\text { days }\end{array}$ & $\begin{array}{l}\text { Successful implantation }(95.6 \%) \text {, cardi- } \\
\text { ac tamponade }(1.02 \%) \text {, procedure-re- } \\
\text { lated stroke }(0.078 \%) \text {, device emboli- } \\
\text { zation }(0.24 \%) \text {, procedure-related } \\
\text { deaths }(0.078 \%)\end{array}$ \\
\hline
\end{tabular}

Post WATCHMAN (Boston Scientific) antithrombotic protocol includes warfarin for 6 weeks followed by clopidogrel for 4.5 months and indefinite aspirin use. Post AMPLATZER (St. Jude Medical) antithrombotic protocol includes aspirin and clopidogrel for 3 months followed by indefinite aspirin use.

LAAC, left atrial appendage closure; PROTECT AF, Watchman Left Atrial Appendage System for Embolic Protection in Patients with Atrial Fibrillation; NVAF, nonvalvular atrial fibrillation; $\mathrm{CHADS}_{2}$, congestive heart failure, hypertension, age $\geq 75$ years, diabetes mellitus, stroke (double weight); LAA, left atrial appendage; INR, international normalized ratio; TTR, time in therapeutic range; ICH, intracranial hemorrhage; GI, gastrointestinal; PREVAIL, Watchman LAA Closure Device in Patients with Atrial Fibrillation Versus Long Term Warfarin Therapy; FDA, U.S. Food and Drug Administration.
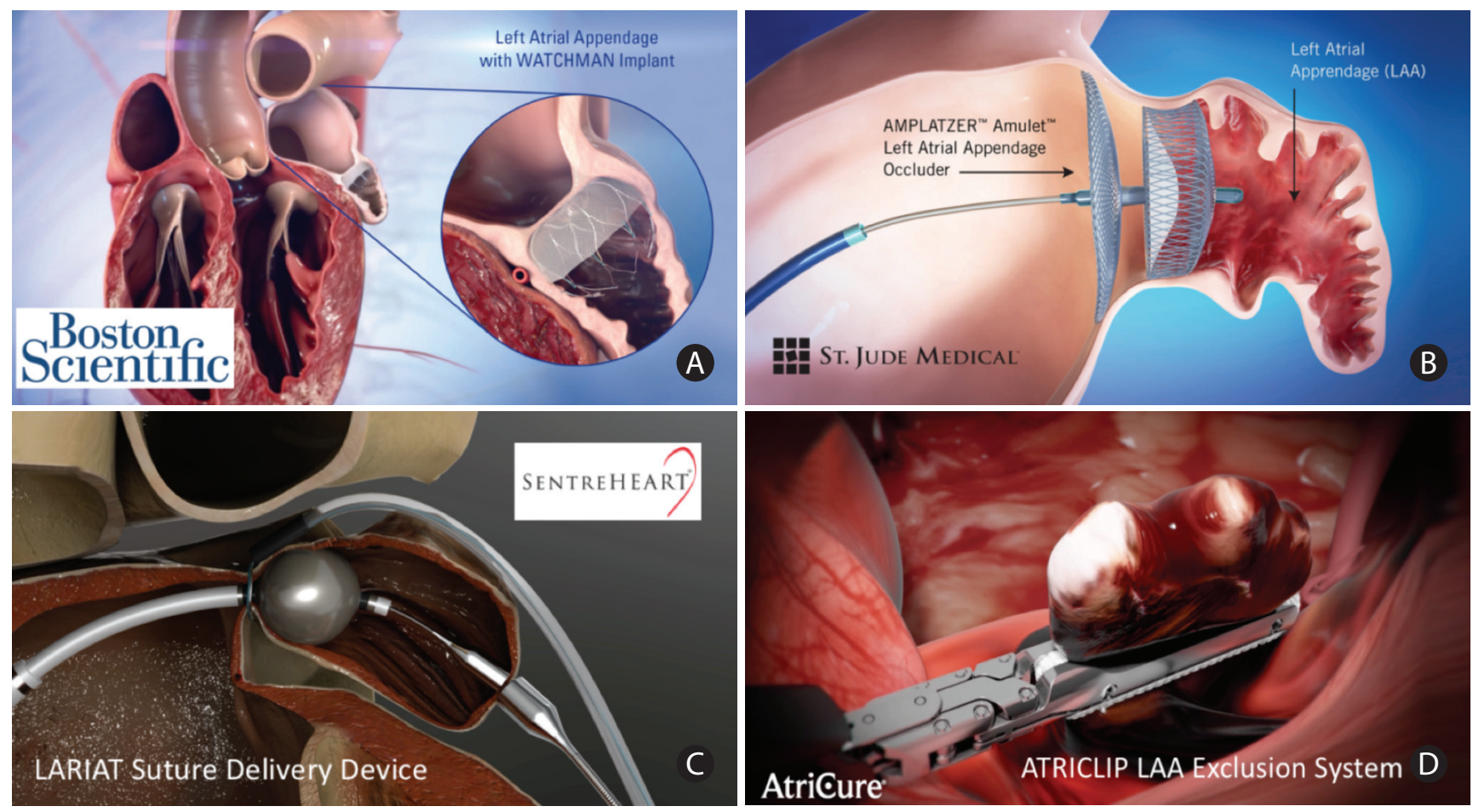

Figure 2. Left atrial appendage (LAA) closure devices and schematics of their deployment. Different types of LAA closure devices are seen. Endocardial devices include (A) WATCHMAN ${ }^{\text {TM }}$ (image provided courtesy of Boston Scientific, c2018 Boston Scientific Corporation or its affiliates, http://www.bostonscientific.com) and (B) AMPLATZER ${ }^{\text {TM }}$ AMULETTM (reproduced with permission of St. Jude Medical, c2018, https://www.sjmglobal.com). (C) The hybrid (endocardial and epicardial) LARIAT ${ }^{\text {TM }}$ suture delivery system for LAA exclusion (reproduced with permission of SENTREHEART, c2018, http://www.sentreheart.com) and (D) AtriClip ${ }^{\text {TM }}$ for surgical clipping (reproduced with permission of AtriCure, c2018, https://www.atricure.com). Devices are trademarks of their respective companies, all rights reserved. 
tained on aspirin. WATCHMAN is commonly used in NVAF patients at higher hemorrhagic risk and the post-marketing experience has shown a favorable safety profile (Table 1). ${ }^{36}$

AMPLATZER AMULET (St. Jude Medical, St. Paul, MN, USA) device (Figure 2B), a different type of pure endocardial LAA Occluder (St. Jude Medical) showed good safety profile in one observational study; an RCT comparing its safety and efficacy against WATCHMAN is currently underway. ${ }^{37}$ Another interesting feature of AMPLATZER AMULET device is that the observational studies mostly used 3 months of dual antiplatelets with acceptable safety profile. LARIAT suture delivery system (SentreHeart, Redwood City, CA, USA) provides a hybrid approach that involves both endocardial and epicardial access, that does not leave any foreign object within the heart (Figure 2C). ${ }^{38}$ As a result, the observational studies used only aspirin after successful LAA exclusion with LARIAT. Currently the AMAZE trial aimed at comparing the safety and efficacy of LARIAT based LAA ligation together with pulmonary vein isolation (PVI) to PVI without LAA exclusion is ongoing. This study will provide information on LARIAT procedure use in conjunction with PVI compared to PVI alone. Another device, the AtriClip (AtriCure, Mason, $\mathrm{OH}$, USA) is used during cardiac surgeries to clip the LAA (Figure 2D). The device has shown higher success rates (>95\%) than surgical ligation or stapling. ${ }^{39}$ Overall, the procedural risks such as pericardial effusion, device embolization, stroke, and death should be discussed with every patient planning to undergo LAAC. LAAC methods have become an important aspect of stroke prevention in NVAF patients at high hemorrhagic risk.

The final stroke prevention approach in NVAF should always be determined based on a shared decision-making meeting with the patient and family, after a thorough discussion of concurrent risks and benefits of different approaches.

\section{Secondary stroke prevention in patients with patent foramen ovale}

PFO is frequently detected in patients with ischemic stroke. While PFO is convincingly responsible for the etiology in some stroke patients, it may also be considered an incidental finding in others. PFO has regained attention in stroke practice after announcement of the positive percutaneous PFO closure studies in 2017 (Table 3 and Figure 3). 4-6,40,41 However, incorporating this preventive approach into daily clinical practice is challenging. Well-known causes of ischemic stroke such as large vessel disease, AF and cerebral small vessel disease should be appropriately ruled out with detailed testing before attributing a stroke to PFO. Such testing might involve long-term cardiac monitoring with ICM in addition to routinely performed brain magnetic resonance imaging (MRI) and cardiovascular testing such as computed tomography angiography (CTA)/magnetic resonance angiography (MRA) and echocardiography. If one of these more common etiologies is confirmed, preventive measures should be selected accordingly. Once the known stroke etiologies are ruled out, the potential cause-and-effect relationship between PFO and stroke should be reviewed. This section thus starts with a concise but adequately detailed review of the connection between PFO and stroke.

PFO is an interatrial foramen that provides a conduit for left atrial blood flow from the right atrium in fetal life, expected to close soon after initiation of breathing at birth. However, complete closure does not happen in about one-fourth of the general population. ${ }^{42}$ When PFO remains open, it is not a real holelike aperture, but rather a door-shaped channel. The blood passage through this door, called as right-to-left shunt (RLS), occurs after increase in the right atrial pressures if not present in the resting state. The major mechanism of ischemic stroke in the setting of PFO is "paradoxical embolism," in which the thromboembolic material originating from veins in the leg reaches the cerebral circulation after passing through the PFO because of RLS. Ischemic strokes may also be caused by embolism due to in situ thrombus formation in the PFO channel and/ or PFO-related atrial cardiomyopathy and/or arrhythmia associated with the latter.

Definitive prevention of recurrent paradoxical embolism is achieved by closure of the PFO (Figure 3). Therefore, clarification of the role of PFO in the occurrence of otherwise idiopathic cerebral embolism is of critical importance. Broadly, ischemic stroke related to PFO can occur as a result of either: (1) thrombus formation in or around the PFO or (2) more commonly from paradoxical embolism of thrombus formed in the venous system traveling through the PFO because of RLS.

The presence of high risk PFO features might be associated with thrombus formation in situ. These features include several morphological and physiological characteristics such as large flow of RLS, presence of long, wide or irregular PFO channel, massive shunting at rest, atrial septal hypermobility, atrial septal aneurysm (ASA), complex right atrial structures such as Eustachian valve and Chiari's network. ${ }^{43}$ Probably, flow grade of $\mathrm{RLS}$ is the most important one in terms of paradoxical embolism, but presence of any of the other factors can suggest PFO as the site of thrombus formation. ${ }^{44}$

Paradoxical embolism of clot formed somewhere in the venous system would require demonstration of RLS and evidence of venous clot formation or at least a propensity to develop clot formation. The first criterion thus would be elevation of 
Table 3. Summary of multicenter randomized clinical trials on patent foramen ovale closure

\begin{tabular}{|c|c|c|c|c|c|}
\hline Study & Patients & Intervention & Comparison & Outcome & Conclusions \\
\hline $\begin{array}{l}\text { Furlan et al. }(2012)^{40} \\
\text { CLOSURE I trial }\end{array}$ & $\begin{array}{l}\text { PFO with recent ( }<6 \\
\text { months) crypto- } \\
\text { genic stroke or TIA } \\
\text { (18-60 years old) }\end{array}$ & $\begin{array}{l}\text { PFO closure with the } \\
\text { STARFlex Septal Closure } \\
\text { System }{ }^{\oplus} \text {, clopidogrel for } \\
6 \text { months \& aspirin in- } \\
\text { definitely ( } n=447 \text { ) }\end{array}$ & $\begin{array}{l}\text { Warfarin or as- } \\
\text { pirin or both } \\
(n=462)\end{array}$ & $\begin{array}{l}\text { A composite of stroke/ } \\
\text { TIA, death }\end{array}$ & $\begin{array}{l}\text { Lower rate of composite end point in clo- } \\
\text { sure group ( } 5.5 \% \text { vs. } 6.8 \% \text { ) but statisti- } \\
\text { cally not significant ( } 2 \text {-year mean follow- } \\
\text { up) }\end{array}$ \\
\hline $\begin{array}{l}\text { Meier et al. }(2013)^{41} \\
\text { PC trial }\end{array}$ & $\begin{array}{l}\text { PFO with cryptogenic } \\
\text { stroke, TIA, or a pe- } \\
\text { ripheral thrombo- } \\
\text { embolic event ( }<60 \\
\text { years old) }\end{array}$ & $\begin{array}{l}\text { PFO closure with AM- } \\
\text { PLATZER PFO Occluder } \\
\text { ticlopidine/clopidogrel } \\
\text { for } 1-6 \text { months \& aspi- } \\
\text { rin for } \geq 5 \text { months } \\
(n=204)\end{array}$ & $\begin{array}{l}\text { Antiplatelet } \\
\text { therapy or oral } \\
\text { anticoagula- } \\
\text { tion }(n=210)\end{array}$ & $\begin{array}{l}\text { A composite of death, } \\
\text { nonfatal stroke, TIA, } \\
\text { or peripheral embo- } \\
\text { lism }\end{array}$ & $\begin{array}{l}\text { Lower rate of composite end point in clo- } \\
\text { sure group ( } 3.4 \% \text { vs. } 5.2 \% \text { ) but statisti- } \\
\text { cally not significant ( } 4 \text {-year mean follow- } \\
\text { up) }\end{array}$ \\
\hline $\begin{array}{l}\text { Mas et al. }(2017)^{4} \\
\text { CLOSE trial }\end{array}$ & $\begin{array}{l}\text { PFO with recent ( }<6 \\
\text { months) stroke at- } \\
\text { tributed to PFO, and } \\
\text { atrial septal aneu- } \\
\text { rysm or large inter- } \\
\text { atrial shunt (16-60 } \\
\text { years old) }\end{array}$ & $\begin{array}{l}\text { PFO closure, DAPT for } 3 \\
\text { months followed by } \\
\text { antiplatelet therapy in- } \\
\text { definitely }(n=238)\end{array}$ & $\begin{array}{l}\text { Antiplatelet } \\
\text { therapy only } \\
\text { arm }(n=235) \& \\
\text { oral anticoag- } \\
\text { ulation arm } \\
(n=187)\end{array}$ & $\begin{array}{l}\text { Occurrence of fatal or } \\
\text { nonfatal stroke }\end{array}$ & $\begin{array}{l}\text { Significantly lower stroke risk in closure } \\
\text { group compared to antiplatelet arm ( } 0 \% \\
\text { vs. } 6 \% \text { ) but an increased risk of atrial fi- } \\
\text { brillation after closure ( } 4.6 \% \text { vs. } 0.9 \% \text { ). } \\
\text { Stroke rate } 1.5 \% \text { in anticoagulation group } \\
\text { vs. 3.8\% in the matched antiplatelet-only } \\
\text { subcohort (5-year mean follow-up) }\end{array}$ \\
\hline $\begin{array}{l}\text { Saver et al. }(2017)^{5} \\
\text { RESPECT trial }\end{array}$ & $\begin{array}{l}\text { PFO with cryptogenic } \\
\text { ischemic stroke } \\
(<270 \text { days })(18-60 \\
\text { years old })\end{array}$ & $\begin{array}{l}\text { PFO closure with the } \\
\text { AMPLATZER PFO Oc- } \\
\text { cluder }{ }^{\oplus} \text { DAPT for } 1 \\
\text { month followed by as- } \\
\text { pirin only for } 5 \text { months, } \\
\text { then antithrombotic } \\
\text { use per treating physi- } \\
\text { cian }(n=499)\end{array}$ & $\begin{array}{l}\text { Any antiplatelet } \\
\text { therapy or oral } \\
\text { anticoagula- } \\
\text { tion }(n=481)\end{array}$ & $\begin{array}{l}\text { A composite of recur- } \\
\text { rent nonfatal or fatal } \\
\text { ischemic stroke, or } \\
\text { early death after ran- } \\
\text { domization }\end{array}$ & $\begin{array}{l}\text { Significantly lower rate of recurrent isch- } \\
\text { emic strokes ( } 3.6 \% \text { vs. } 5.8 \% \text { ) but higher } \\
\text { venous thromboembolism in the closure } \\
\text { arm ( } 3.4 \% \text { vs. } 0.8 \% \text { ) (5.9-year median } \\
\text { follow-up) }\end{array}$ \\
\hline $\begin{array}{l}\text { Søndergaard et al. } \\
(2017)^{6} \text { Gore RE- } \\
\text { DUCE Clinical } \\
\text { Study }\end{array}$ & $\begin{array}{l}\text { PF0 with cryptogenic } \\
\text { stroke (<180 days), } \\
81 \% \text { with moder- } \\
\text { ate/large interatrial } \\
\text { shunts (18-59 } \\
\text { years old) }\end{array}$ & $\begin{array}{l}\text { PFO closure with the He- } \\
\text { lex Septal Occluder or } \\
\text { the Cardioform Septal } \\
\text { Occluder }{ }^{\oplus}, 300 \mathrm{mg} \\
\text { clopidogrel load then } \\
\text { antiplatelet monother- } \\
\text { apy }(n=441)\end{array}$ & $\begin{array}{l}\text { Any antiplatelet } \\
\text { monotherapy } \\
(n=223)\end{array}$ & $\begin{array}{l}\text { Co-primary end points: } \\
\text { (1) Clinical ischemic } \\
\text { stroke, (2) composite } \\
\text { of clinical ischemic } \\
\text { stroke or silent brain } \\
\text { infarction detected on } \\
\text { imaging }\end{array}$ & $\begin{array}{l}\text { Significantly lower clinical ischemic stroke } \\
(1.4 \% \text { vs. } 5.4 \%) \text { but higher rates of device } \\
\text { complications }(1.4 \%) \text { and atrial fibrilla- } \\
\text { tion ( } 6.6 \% \text { vs. } 0.4 \%) \text { in the closure arm } \\
\text { (3.2-year median follow-up) }\end{array}$ \\
\hline
\end{tabular}

CLOSURE I, Evaluation of the STARFlex Septal Closure System (NMT Medical Inc.) in Patients with a Stroke and/or Transient Ischemic Attack due to Presumed Paradoxical Embolism through a Patent Foramen Ovale; PFO, patent foramen ovale; TIA, transient ischemic attack; PC trial, Clinical Trial Comparing Percutaneous Closure of Patent Foramen Ovale Using the AMPLATZER (St. Jude Medical) PFO Occluder (St. Jude Medical) with Medical Treatment in Patients with Cryptogenic Embolism; CLOSE, Patent Foramen Ovale Closure or Anticoagulants Versus Antiplatelet Therapy to Prevent Stroke Recurrence; DAPT, dual antiplatelet therapy (aspirin and clopidogrel); RESPECT, Randomized Evaluation of Recurrent Stroke Comparing PFO Closure to Established Current Standard of Care Treatment; Gore REDUCE Clinical Study, GORE ${ }^{\circledast}$ HELEX ${ }^{\circledR}$ Septal Occluder and GORE ${ }^{\circledR}$ CARDIOFORM Septal Occluder for Patent Foramen Ovale (PFO) Closure in Stroke Patients.

right atrial and pulmonary artery pressures. This may be permanent, or it may only be elevated temporarily during the onset of stroke. Therefore, any temporary maneuver increasing pressures in the right heart (Valsalva maneuver) such as strain, heavy lifting, forced defecation, coitus, and diving should be questioned carefully in every case with suspicion of paradoxical embolism. Chronic and effortful coughing may also result in increased right atrial and pulmonary pressures. Permanent pulmonary hypertension causes include chronic obstructive pulmonary disease, obstructive sleep apnea, chronic and/or massive pulmonary thromboembolism (PTE), right-sided acute myocardial infarction (AMI), adult respiratory distress syndrome, and the trumpet player syndrome, which is an occupational condition due to chronic and zealous playing of breath- taking instruments such as the trumpet. ${ }^{45}$ The presence of these factors should be assessed whenever PFO is considered as the cause for an ischemic stroke. Demonstration of RLS at rest or with Valsalva on cardiac ultrasonography confirms the propensity for paradoxical embolism.

The second set of criteria for paradoxical embolism are about the presence of deep vein thrombosis (DVT) and/or PTE or demonstration of a hypercoagulable state. For these purposes, the presence of DVT in the lower extremity should be investigated by valid methods such as compression ultrasonography, computed tomography, MRI, contrast venography, or scintigraphy in all cases with cryptogenic stroke and PFO. The presence of thrombus in pelvic, iliac, and caval veins should be assessed by pelvic magnetic resonance venography (MRV) or computed to- 

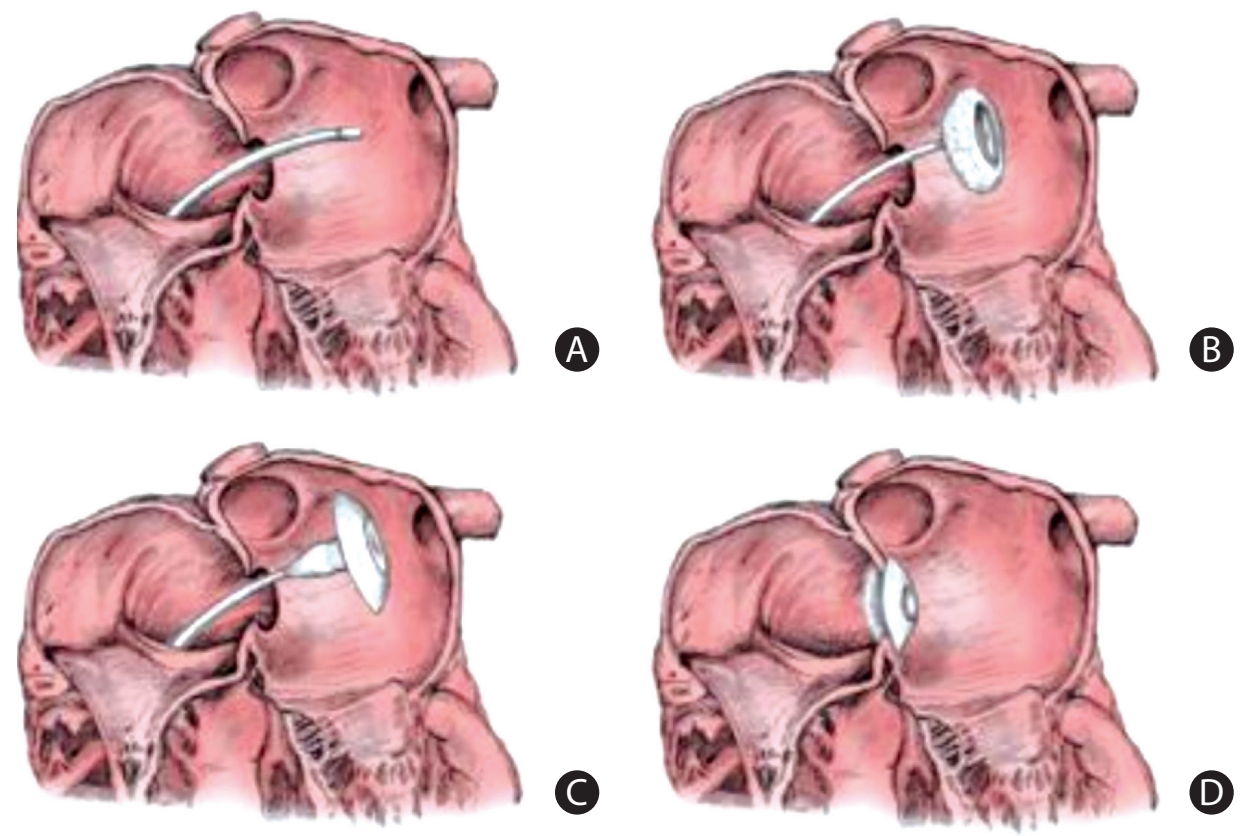

Figure 3. Schematic of patent foramen ovale (PFO) closure. Schematic illustrating the endovascular procedure used to close a PFO using AMPLATZER ${ }^{\text {TM }}$ PFO Occluder (St. Jude Medical). (A) The catheter is inserted through the PFO, (B, C) followed by expansion of the left sided disc and (D) deployment of the device to occlude the PFO (showing the device in place). AMPLATZER and St. Jude Medical are trademarks of St. Jude Medical, LLC or its related companies. Reproduced with permission of St. Jude Medical, c2018 (https://www.sjmglobal.com). All rights reserved.

mographic venography. ${ }^{46}$ Pelvic MRV can also show the presence of May-Thurner anatomy characterized by compression of the left common iliac vein by the overlying right common iliac artery, a condition that can result in compression of the common venous outflow tract of the left lower extremity increasing the risk of DVT. Plasma D-dimer level elevation can be used as a screening tool for DVT diagnosis. ${ }^{47}$ If DVT cannot be documented, this criterion may be met by the presence of DVT risk factors, especially useful in non-acute situations. In other words, the inability to demonstrate DVT does not rule out the possibility of paradoxical embolism. In this context, immobility, occult hereditary thrombophilia, oral contraceptive use, pregnancy and postpartum period, and May-Thurner anatomy increase the risk.

For every patient, activated protein $\mathrm{C}$ resistance, factor- 5 Leiden mutation, antiphospholipid antibody titers, prothrombin 20210 polymorphism, homocysteine levels, and associated methylenetetrahydrofolate reductase mutations, should be tested for thrombophilia detection. Protein $\mathrm{S}$, protein $\mathrm{C}$, antithrombin III and factor VIII concentrations and/or activities should be studied in patients without these factors. ${ }^{48}$ Long plane travel ("economy-class stroke syndrome") is a risk for embolism in patients with $\mathrm{PFO} .^{49}$ In addition, several surgical procedures such as neurosurgical posterior fossa surgery, intramedullary orthopedic surgery, lower limb venous surgery, lipo- suction and any laparoscopy carry high stroke risk if RLS is present. Another important point regarding DVT testing is that DVT may develop very rapidly after stroke onset, and it is absolutely necessary to carry out the examination within the first few days after stroke (or immobility) onset. If the DVT is detected later, it cannot be established whether the DVT is either the cause or the result of the stroke. Even if the initial stroke is not due to PFO, the development of DVT confers a high-risk status for stroke recurrence in paretic stroke patients with PFO. Ttranscatheter PFO closure may sometimes be considered in such situations as well.

Current options to prevent ischemic stroke recurrence attributed to PFO include antiplatelet medications, anticoagulants, and transcatheter PFO closure. The choice between antiplatelet and anticoagulant agents for secondary prophylaxis is based on the status of the systemic and hematological factors. It should be noted that there is no significant difference for ischemic prevention between the two groups of drugs in the absence of thrombophilia or DVT/PTE. ${ }^{50}$ Long-term use of OACs would increase the risk of hemorrhagic complications and most importantly fatal/disabling $\mathrm{ICH} .{ }^{3}$ On the other hand, if a hypercoagulable state that requires life-long anticoagulation such as anticardiolipin antibody syndrome is found, long-term anticoagulation is the only option although PFO closure might still have a role in these situations. It is important to remember that medical man- 
agement should involve aggressive detection and control of all vascular risk factors in patients with PFO and stroke.

Five recently-published RCTs showed that transcatheter PFO closure plus antiplatelet treatment is superior to antiplatelet therapy alone for secondary stroke prevention (Table 3 and Figure 3). ${ }^{4-6,40,41}$ These studies showed that the frequency of recurrent embolic stroke can be reduced from 1.1 to 0.53 per 100 patient-years with the transcatheter PFO closure, corresponding to $50 \%$ relative risk reduction, $2.11 \%$ absolute risk reduction, and a number needed to treat of 46.5 over about 4 years followup. ${ }^{51-53}$ There was no significant difference in the risk of transient ischemic attack, mortality and bleeding rates between transcatheter PFO closure and antiplatelet-only approaches. The most noticeable adverse effect during post-transcatheter PFO closure period is an increase in the frequency of $A F$ ( 1.3 vs. 0.25 in 100-patient years, referring to an approximately five times relative risk increase)..$^{51}$ Many of the $\mathrm{AF}$ episodes are transient and limited to the periprocedural phase. Indeed, three quarters of these post-transcatheter PFO closure AF episodes occur within 45 days, and almost all disappear in up to 6 months. It is recommended for these patients to receive anticoagulants for 6 months, provided that persistent normalization of the rhythm can be confirmed. The studies assessing PFO closure used only a simple EKG or short-term Holter to rule out concomitant AF; so, the extent of $A F$ in these patients is not well-known. In addition, an increase in venous thromboembolism frequency was noted in cases of switching anticoagulants to antiplatelets after PFO closure in patients with thrombophilia.

Despite the high popularity in medical and lay social media, these recent data did not change routine clinical practice in PFO management. Some of the concerns voiced are that: (1) none of these studies was completely blinded; (2) the rates of lost to follow-up and withdrawal of consent were high; (3) the enrollment criteria were heterogenous and restrictive; and (4) different devices and especially different antithrombotic regimens were used. ${ }^{54,55}$

In the light of the findings summarized above, we believe that transcatheter PFO closure is indicated in a number of clinical scenarios. In case of PFO and otherwise cryptogenic embolism, PFO should be closed if recurrence occurs despite medical treatment. These patients should continue taking antiplatelet medication thereafter. Anticoagulant therapy should be used after first embolic event in cases with thrombophilia or documented DVT/PTE. If a recurrence occurs despite well-managed anticoagulation, the PFO should then be closed. Standard thrombosis management guidelines should be applied for medical treatment selection. PFO closure may be reasonable in some instances after the first embolic episode. Cerebral MRI, obtained during the index stroke, documenting one or more previous embolic (cortical) infarcts, contraindications to use of long-term anticoagulants or antiplatelets and high-risk features of PFO would support PFO closure especially in the young patient with high-flow RLS. Waiting for recurrence, that is, a second stroke with associated disability/death risks, would not be rational in these cases. It is appropriate to reiterate that there are no data suggesting that every PFO should be closed following the first embolic event. PFO closure for primary prophylaxis is not recommended for any reason including migraine with aura in subjects who never experienced clinical paradoxical embolism, as there are no objective data showing the benefit of closure in these situations.

In patients with stroke due to PFO, the risk of embolism recurrence is very low after complete PFO closure. It is well known that shunt retention after percutaneous PFO closure is about $10 \%$. However, these residual shunts do not lead to an increased embolism risk because their sizes are very small, and their apertures are meshed with the device. ${ }^{56}$ Therefore, if there is an ischemic stroke recurrence after percutaneous PFO closure, it is more likely to be related to a different etiologic mechanism. It should be remembered that PFO closure would only prevent ischemic strokes attributable to PFO and decrease the risk of bleeding related to long-term anticoagulant use. In conclusion, the PFO stroke relationship must be carefully assessed for each patient, and treatment decisions should involve a multidisciplinary team as well as a formal shared decisionmaking process.

\section{Stroke in infective endocarditis}

IE is a microbial infection of the cardiac endocardial surface including valves (native and prosthetic) and pacemakers/implantable cardioverter-defibrillator (ICD) wires. The vast majority of IEs are bacterial, while only a few are fungal. Culture remains negative in up to one-fifth of IE cases. The incidence of IE is about 3 to 10 per 100,000. A predisposing heart disease is found in approximately $75 \%$ of cases. ${ }^{57}$ Various IE classifications are available. For practical purposes, IE is divided into four groups: (1) left-sided native valve IE (NVIE); (2) left-sided prosthetic valve IE (PVIE), further classified as early, if developed in the first year after valve implantation, or late thereafter; (3) right-sided IE; and (4) device-related IE. Right-sided IE is usually associated with intravenous (IV) drug use and causes fewer neurovascular complications if confined to the right heart. The most frequent cause of acute IE, which is overall less common (up to 20\%) compared to other type IEs is Staphylococcus aureus (SA). SA-IE usually occurs in natural valves, re- 
sulting in a more rapidly progressive and destructive infection. The most common cause of subacute NVIE is viridans group streptococcus (VGS), which causes an erosive IE that frequently develops on previously diseased and deformed valves. The most common cause of PVIE is coagulase negative staphylococcus. ${ }^{58}$

Significant systemic symptoms of IE are related to fever, $\mathrm{HF}_{\text {, }}$ valve insufficiency, cerebral and peripheral embolism. Neurological involvement associated with IE is common, and diverse. Approximately half of IE patients have neurological complaints at admission including focal deficits, encephalopathy, and epileptic seizures. Cerebral abscesses and meningitis are not uncommon. Symptomatic neurovascular events include septic (infectious) cerebral embolism, central nervous system (CNS) hemorrhages, and mycotic aneurysms. Neurological complications are more prevalent in the early course, usually before initiation of the first dose of antibiotics, and their occurrence generally indicates poorer prognosis. In this section, we will focus on cerebral septic embolism, IE-related CNS hemorrhages, and intracranial mycotic aneurysms (ICMAs). With advances in MRI techniques, previously less well-known pathologies such as microbleeds, superficial siderosis and smaller infarcts are commonly detected nowadays in IE clinical practice necessitating neurology consultations.

The frequency of systemic embolism in IE is $22 \%$ to $50 \%$. Approximately two-thirds of these embolizations involve cerebral circulation. The middle cerebral artery (MCA) territory is affected in up to $90 \%$ of IE cases with stroke. Diffusion MRI studies have shown that cerebral microembolisms are present in almost every IE case, albeit mostly clinically occult. ${ }^{59}$ Mitral valve involvement is associated with a high risk of stroke, especially if anterior leaflets are infected. SA, candida, and HACEK (Haemophilus species, Aggregatibacter species, Cardiobacterium hominis, Eikenella corrodens, and Kingella species) group organisms are linked to higher embolism risk. Response of vegetation to the antibiotic treatment is critical. Growth of vegetation under antibiotic treatment without shrinkage after 4 to 8 weeks of treatment are significant risk factors along with several morphological vegetation features such as high mobility, irregular shape, sessile, and loose attachment. Embolism risk increases if the size of left-sided vegetation is greater than $1 \mathrm{~cm}$, albeit it is stated that this may be a more relevant criterion for VGS IE. ${ }^{60}$ Stroke frequency is significantly reduced after 2 to 3 weeks of effective IV antibiotic therapy. Such decrease in risk is independent of IE location and offending microorganism type..$^{58}$ Non-infectious CE may also occur in the setting of IE due to associated cardiac diseases.

An important current discussion topic in IE is about the value of cerebral MRI in the clinical decision-making processes. ${ }^{61} \mathrm{Ce}-$ rebral MRI may be considered in all patients with left-sided IE even in the absence of CNS signs and symptoms. In a seminal French study, MRI documented at least one category of lesions in $82 \%$ of 106 IE patients, including ischemic lesions in 68 , microhemorrhages in 74, and silent aneurysms in 10, albeit only $12 \%$ of them had acute neurologic symptoms. ${ }^{62}$ Brain MRI findings (microinfarcts, cerebral microbleeds [CMBs], ICMAs, and leptomeningeal contrast enhancement) may assist in not only tailoring subsequent medical and surgical management, but also clarification of ischemic/hemorrhagic risks. MRI frequently shows multi-territorial cortical and subcortical embolic infarcts of various diameter in IE. The more specific forms are numerous, multi-territorial, punctate infarcts creating a "starry-sky view on diffusion-weighted imaging (DWI)" and combination of multiple microinfarcts and microabscesses. ${ }^{63}$ Clinically, multifocal and poorly localized symptoms and signs are frequent. Focal findings and encephalopathy can be seen together. A non-focal embolic encephalopathy is a less common, but more typical manifestation of IE. ${ }^{63}$

Acute ischemic stroke management in IE differs from other diseases in many respects. Firstly, standard IV tissue plasminogen activator administration in the acute phase is not safe due to high bleeding rates so this approach should be avoided. ${ }^{64}$ Experience indicates that mechanical thrombectomy can be performed more safely in the setting of IE. ${ }^{65}$ In addition, anticoagulant treatment is highly perilous before complete control of infection (confirmed by three negative blood cultures) and confirmation of the lack of mycotic aneurysms or other pathology associated with high ICH risk. The risk of CNS hemorrhagic complications due to anticoagulants may not be completely excluded even with documentation of absence of cerebral septic vasculitis and/or mycotic microaneurysms with cerebral catheter angiography. While it might decrease the risk of noninfected embolism from concomitant AF, if present, anticoagulation does not prevent septic emboli and associated infarcts. Antiplatelets have no role. In these patients, valve surgery can be performed after stabilization of the infection and ruling out a high hemorrhagic risk cerebral pathology such as ICMA. The most important issues are always rapid diagnosis and initiation of appropriate antibiotics in addition to source control.

The frequency of hemorrhagic stroke is lower than ischemic events in IE but indeed outcomes of ICH are dismal. Almost every type of CNS hemorrhage such as intraparenchymal, subarachnoid (SAH), subdural hematomas and hemorrhagic infarction can be seen in IE. Mitral valve involvement, SA positivity and large $(\geq 30 \mathrm{~mm})$ vegetations are usually linked to CNS hemorrhage. ${ }^{66}$ Anticoagulation before infection control and before ruling out ICMA or other high-risk lesions is a well-recognized 
risk factor for CNS hemorrhage. Importantly, the cardiac and neurological prognosis of IE-related hematomas is poor.

Two types of CNS hemorrhage merit further mentioning. The first is convexal, or cortical SAH (frequency, about 10\%), which may be related to distal mycotic microaneurysm or septic arteritis. In cases with MRI-documented convexal SAH or cortical siderosis, catheter angiography should be performed. ${ }^{67}$ The other subtle hemorrhagic pathology is CMBs which have a documented frequency of around $60 \%$ in IE based on consecutive MRI studies. These CMBs have been linked to PVIE rather than prior anticoagulant use. ${ }^{68} \mathrm{IE}$-associated CMBs show several different features such as more superficial localization, larger size and heterogeneous appearance. ${ }^{69}$ These are not usually due to mycotic aneurysms, but inflammatory distal arteritis from septic microembolism. The number and localization of CMBs do not correlate with DWI positive microinfarcts. The presence of CMBs is a strong predictor of impending CNS hemorrhage in early phases of IE. However, after successful control of infection, this risk disappears and no further increase in CMBs is anticipated. After full infection control, the risk of long-term anticoagulation might also be reduced to a reasonable degree. Therefore, CMBs may not be considered as a concrete contraindication to anticoagulant use when indicated in these cases, once the infection is adequately treated. ${ }^{70}$

The incidence of ICMA in IE is between 1\% to $10 \%{ }^{71,72}$ ICMAs are more commonly seen in patients with sepsis, human immunodeficiency virus, and IV drug use and relative immunocompromised states such as diabetes. Not only incidence, but also risk of rapid growth and rupture increases in immune-suppressed IE patients. ${ }^{71}$ Clinical manifestations of ICMAs are highly variable, similar to other neurovascular manifestations of IE. Fever is seen in only $20 \%$ of cases with ICMAs, while focal neurological deficit and meningeal irritation signs are noted in $40 \%$ along with headache in $60 \%$. ICMAs present with SAH in $40 \%$, infarct in 30\%, and lobar hemorrhage in another 30\%, usually in combination. Of note, symptomatic infected cerebral emboli frequently, but not invariably, precede the ICMA formation. In cases with CNS hemorrhage in the setting of $I E$, the likelihood of ICMA is around 20\%, and 1\% in non-hemorrhagic cases. A catheter angiography should therefore be performed for every case with IE associated CNS hemorrhage. CTA cannot replace catheter angiography as the sensitivity of CTA varies between $45 \%$ to $85 \%$ if the diameter of the aneurysm is $3 \mathrm{~mm}$ or less, albeit it might reach 100\% for aneurysms greater than $3 \mathrm{~mm}^{73}$ ICMAs are always linked to poor prognosis in IE. Their rupture corresponds to approximately $80 \%$ mortality rate, while mortality is about $30 \%$ in patients with unruptured ICMAs. ${ }^{72}$

The cerebral mycotic aneurysms are typically thin-walled and fragile. Rupture rate is variable (between $2 \%$ to $80 \%$ ) with an average of 50\%. However, according to some authorities, rupture risk may be lower than these estimates. No predictive factors for mycotic aneurysm rupture have been identified. It is well documented that the size of the aneurysm is not directly related to the risk of rupture. ${ }^{74}$ The average diameter of ICMAs is around $4 \mathrm{~mm}$. The shapes are generally fusiform and irregular. Saccular geometry is less common. The most typical feature is their dynamic morphology; change in shape, growth, shrinkage and emergence of new aneurysms during follow-up strongly suggests an infectious cause. ${ }^{75}$ ICMAs mostly develop in the distal cerebral vasculature. The main cause of these distal mycotic aneurysms is septic embolism. Rare occurrence of proximal mycotic aneurysms is usually associated with focal meningitis. MCA territory is involved in 70\% of the cases. ICMAs are multiple in about one-fourth of patients. ${ }^{72,74}$ Streptococci species are the most frequent causative organisms, found in approximately 50\% of patients with ICMA in whom a microorganism could be detected. SA is isolated in about $10 \%$ of these patients. ${ }^{60}$

The main component of ICMA management is parenteral antibiotics. ${ }^{57}$ With intensive antibiotic therapy, the aneurysm is expected to shrink and subsequently disappear. However, obliteration of an ICMA should be performed when an open-heart surgery such as emergency valve replacement is needed. Since anticoagulation is not permitted and HF usually worsens during post-craniotomy period, endovascular treatment methods are preferred to neurosurgical approaches. ${ }^{58}$ Unless ICMAs are located in eloquent areas such as motor cortex, occlusion of the parent artery proximal to the aneurysm is often the procedure of choice. ${ }^{58}$ This approach is not always easy whenever such artery supplies a functionally important region. Discussing these difficult situations between neurology, cardiology, interventional neurology, and cardiothoracic surgery experts and involving the patient in clinical decision making is important.

\section{Heart failure and stroke}

$\mathrm{HF}$ is currently grouped into two: HF with reduced ejection fraction (EF), previously called "systolic HF," and HF with preserved EF, previously called "diastolic HF." Low EF is diagnosed when it is less than $40 \%$, while normal EF is higher than $50 \%$. Values from 40\% to 50\% are described as "mid-range" EF. ${ }^{76}$

Prevalence of both types of HF is high, between $10 \%$ to $25 \%$, in stroke cohorts. Functional outcomes and survival rates are significantly worse in stroke patients with HF. Major risk factors of $\mathrm{HF}$ are hypertension, coronary artery disease, heart valve diseases, AF and diabetes, all of which are also important risk/etio- 
logical factors for stroke individually. Risk factors for stroke in HF patients without AF are previous stroke history, severity of HF symptoms, insulin-dependent diabetes mellitus, body mass index, and age. Elevation of B-type natriuretic peptide may also indicate an increased risk. ${ }^{77}$ In addition to frequently coexistent pathologies such as atherosclerotic arterial disease and AF, HF can cause stroke itself via intracardiac stasis related thromboembolism along with low-cardiac output-related cerebral hypoperfusion and reduced cerebral autoregulation capacity. ${ }^{76}$

For HF patients with AF, anticoagulation is generally recommended based on other embolic risk factors and the absence of concurrent hemorrhagic risk. If no AF, then the benefit of anticoagulation is not clear. In a meta-analysis of four trials, including Warfarin versus Aspirin in Reduced Cardiac Ejection Fraction (WARCEF) ${ }_{1}^{78}$ warfarin reduced ischemic stroke frequency from 1.36 to 0.72 events per 100 patient-years compared to aspirin. Unfortunately, this potential benefit was negated by a significant increase in major bleeding rates from 0.87 to 1.78 events per 100 patient-years. In addition, no improvement has been observed in survival rates with warfarin. ${ }^{76}$ However, NOACs, with well-established lower bleeding rates, may be potentially useful for this indication and merit further research. COMMANDER HF is a currently ongoing phase III trial aiming to test rivaroxaban versus placebo for reducing the risk of death, myocardial infarction (MI), or stroke in patients with chronic HF and significant coronary artery disease after a recent HF-related hospitalization.

Standard management of HF include diuretics such as mineralocorticoid receptor antagonist, thiazide and loop diuretics along with optimization of comorbidities such as pulmonary disease, anemia, and sleep disordered breathing. For HF with reduced $E F$, effective hypertension control with $\beta$ blocker, angiotensin converting enzyme inhibitor, angiotensin II receptor blocker, angiotensin receptor-neprilysin inhibitor, mineralocorticoid receptor antagonist, and nitrates are usually suggested. Cardiac revascularization with angioplasty or bypass surgery and valvular repair, if needed, may be useful in selected patients. ICDs can be used for prevention of sudden cardiac death. Cardiac resynchronization therapy with biventricular pacing may also improve survival in some patients. It is important to note that use of left ventricular assist device pumps (LVADP) causes significant coagulation activation and diminished pulsatility and therefore mandates anticoagulation as well as antiplatelet use. ${ }^{79}$ Newer LVADP such as the HeartMate ${ }^{\circledR}$ (St. Jude Medical) decrease pump thrombosis, but not stroke rates. ${ }^{80}$ Clinicians should be aware of the neurological risk of high-intensity warfarin and combination antithrombotic use, especially for HF patients at high baseline hemorrhagic risk when LVADP is considered.

\section{Valve replacement and stroke}

Life-long OAC therapy is mandatory in the setting of prosthetic mechanical heart valves to prevent valve thrombosis, systemic and cerebral embolism. The incidence of major bleeding is around 1.4 per 100 patient-years in patients treated with coumarin derivatives. ${ }^{81}$ In the setting of major risk for anticoagulant-related bleeding, such as elderly with cerebral amyloid angiopathy, a primary valvular repair, bioprosthesis, or transcatheter aortic valve replacement are preferred instead of mechanical valve. It is also reasonable to insert MRI-compatible prostheses in patients with a high risk of stroke.

In observational studies, reinstitution of anticoagulation was associated with a lower risk of thromboembolic complications compared to no anticoagulation. ${ }^{82}$ In cases who need to resume oral anticoagulation after a hemorrhage, the risk of rebleeding might be reduced with more strict INR control, effective blood pressure management, careful countermeasures against falls, avoidance of unnecessary addition of antiplatelet medicines and structured patient education including diet and medication interactions. ${ }^{83}$ Self-monitoring or self-management of oral anticoagulation therapy such as home-based testing can improve life quality and decrease risk of thromboembolic complications. Of note, all-cause mortality is reduced with self-management but not self-monitoring. Importantly, selfmonitoring or self-management have no effects on the occurrence of major hemorrhage. ${ }^{84}$

Generally, OAC agents are restarted in 4 to 8 weeks after an $\mathrm{ICH}$ when there are no alternatives to reduce the risk of systemic/cerebral thromboembolism due to thrombosis of the prosthetic valves. In such cases, the period before restarting anticoagulation should be individualized, taking into account both ischemic and hemorrhagic risks. For cases with high risk of thromboembolism due to mechanical valves, it is imperative to wait at least for the stabilization of the size of the $\mathrm{ICH}$ but OACs may need to be resumed as early as 7 days after the brain hemorrhage.

\section{Coronary artery disease and stroke}

The association between coronary artery disease and stroke is well-known; both in the early period after an AMI and in patients with chronic coronary artery problems. This association remains relevant despite improvement in vascular reperfusion methods and the management of cardiovascular risk factors. The rate of in-hospital stroke after AMI ranges from $0.7 \%$ to 
$2.2 \%{ }^{85} \mathrm{ICH}$ after AMI has a reported incidence between $0.06 \%$ to $0.22 \%$. Stroke after AMI remains associated with poor outcomes with a 1-year mortality of $36.5 \% .{ }^{86}$ Segmental wall motion abnormalities and aneurysm formation within the left ventricular wall and development of transient or permanent arrhythmias both in acute and chronic stages after an ischemic myocardial event can trigger an embolic stroke. The frequent use of fibrinolytics, anticoagulants, and multiple antiplatelet medications in this older patient population can certainly increase the risk of $\mathrm{ICH}$ as well.

All patients with coronary artery disease should receive optimal treatment to correct vascular risk factors including hypertension, diabetes, hyperlipidemia, smoking, and sedentary life style to name a few. Concurrent morbidities such as AF, other dysrhythmias and HF should be optimally treated. The choice and duration of antithrombotic treatment should be primarily determined based on the type of coronary intervention that the patient might need such as balloon angioplasty, stenting, or coronary artery bypass grafting. ${ }^{87}$

Recent studies have shed light on use of simplified shortterm anticoagulation regimens in patients with AF who undergo percutaneous coronary interventions. The use of a lower dose NOAC (rivaroxaban or dabigatran) and single antiplatelet agent provided comparable results to the standard triple therapy that includes warfarin, aspirin and clopidogrel in these patients, in terms of safety and efficacy. ${ }^{88,89}$ Another recent study evaluated the effects of rivaroxaban with or without aspirin in stable cardiovascular disease, in a design that not only excluded patients with past history of $\mathrm{ICH}$ but also symptomatic lacunar cerebral infarcts, to decrease anticoagulant-related ICHs. This study showed that in patients with stable cardiovascular disease ( $>90 \%$ of them with coronary artery disease), the combination of rivaroxaban $2.5 \mathrm{mg}$ twice daily and aspirin prevented a composite outcome of cardiovascular death, stroke, or MI more than aspirin alone ( $4.1 \%$ vs. $5.4 \%$ ). However, there were more major bleeding events in the rivaroxaban-plus-aspirin group (3.1\% vs. $1.9 \%$ ). ${ }^{90}$ This review of recent data therefore demonstrates that stroke and cardiovascular prevention in patients with coronary artery disease remains a rapidly evolving field. Understanding the concurrent ischemic/hemorrhagic risks and other relevant pathologies in the individual patient remains very important to provide optimal stroke prevention approaches.

\section{Conclusions}

The last decade brought important progress in our understanding of cardioembolic conditions and major advances in stroke prevention within this context. The familiarity of neurology and stroke specialists with these conditions is critical as these experts primarily evaluate stroke patients to understand the etiology of stroke and stratify future ischemic and hemorrhagic risks. Multidisciplinary collaborations also require familiarity with these advances, as parties involved (neurologist, cardiologist, cardiothoracic surgeon) should be able to understand the available approaches and challenges in order to provide the best clinical management to the individual patient.

\section{Disclosure}

The authors have no financial conflicts of interest.

\section{Acknowledgments}

This work was made possible by grants from the National Institute of Health (M. Edip Gurol, NS083711). Dong-Eog Kim was supported by Ministry of Health \& Welfare (HI12C1847; Korea Healthcare Technology R\&D Project), funded by the Korean government, Republic of Korea.

\section{References}

1. Gokcal $E_{1}$ Pasi M, Fisher M, Gurol ME. Atrial fibrillation for the neurologist: preventing both ischemic and hemorrhagic strokes. Curr Neurol Neurosci Rep 2018;18:6.

2. Steffel J, Verhamme P, Potpara TS, Albaladejo P, Antz M, Desteghe $L_{\text {, et al. The }} 2018$ European Heart Rhythm Association practical guide on the use of non-vitamin $\mathrm{K}$ antagonist oral anticoagulants in patients with atrial fibrillation. Eur Heart $J$ 2018;39:1330-1393.

3. Gurol ME. Nonpharmacological management of atrial fibrillation in patients at high intracranial hemorrhage risk. Stroke 2018;49:247-254.

4. Mas JL, Derumeaux G, Guillon B, Massardier E, Hosseini $H_{\text {, }}$ Mechtouff $L$, et al. Patent foramen ovale closure or anticoagulation vs. antiplatelets after stroke. N Engl J Med 2017;377: 1011-1021.

5. Saver JL, Carroll JD, Thaler DE, Smalling RW, MacDonald LA, Marks DS, et al. Long-term outcomes of patent foramen ovale closure or medical therapy after stroke. N Engl J Med 2017;377:1022-1032.

6. Søndergaard L, Kasner SE, Rhodes JF, Andersen G, Iversen HK, Nielsen-Kudsk et al. Patent foramen ovale closure or antiplatelet therapy for cryptogenic stroke. N Engl J Med 2017; 377:1033-1042.

7. Krishnamurthi RV, Feigin VL, Forouzanfar MH, Mensah GA, Connor M, Bennett DA, et al. Global and regional burden of 
first-ever ischaemic and haemorrhagic stroke during 19902010: findings from the Global Burden of Disease Study 2010. Lancet Glob Health 2013;1:e259-e281.

8. Tsai HH, Kim JS, Jouvent E, Gurol ME. Updates on prevention of hemorrhagic and lacunar strokes. J Stroke 2018;20:167179.

9. January CT, Wann LS, Alpert JS, Calkins H, Cigarroa JE, Cleveland JC Jr, et al. 2014 AHA/ACC/HRS guideline for the management of patients with atrial fibrillation: a report of the American College of Cardiology/American Heart Association Task Force on practice guidelines and the Heart Rhythm Society. Circulation 2014;130:e199-e267.

10. Kirchhof $P$, Benussi $S$, Kotecha D, Ahlsson A, Atar D, Casadei $B$, et al. 2016 ESC guidelines for the management of atrial fibrillation developed in collaboration with EACTS. Eur Heart J 2016;37:2893-2962.

11. McManus DD, Rienstra M, Benjamin EJ. An update on the prognosis of patients with atrial fibrillation. Circulation 2012;126:e143-e146.

12. Benjamin EJ, Blaha MJ, Chiuve SE, Cushman M, Das SR, Deo $R$, et al. Heart disease and stroke statistics-2017 update: a report from the American Heart Association. Circulation 2017;135:e146-e603.

13. Gage BF, Waterman AD, Shannon W, Boechler M, Rich MW, Radford MJ. Validation of clinical classification schemes for predicting stroke: results from the National Registry of Atrial Fibrillation. JAMA 2001;285:2864-2870.

14. Lip GY, Nieuwlaat R, Pisters R, Lane DA, Crijns HJ. Refining clinical risk stratification for predicting stroke and thromboembolism in atrial fibrillation using a novel risk factor-based approach: the Euro heart survey on atrial fibrillation. Chest 2010;137:263-272.

15. Singer DE, Chang $Y$, Borowsky LH, Fang MC, Pomernacki NK, Udaltsova $\mathrm{N}$, et al. A new risk scheme to predict ischemic stroke and other thromboembolism in atrial fibrillation: the ATRIA study stroke risk score. J Am Heart Assoc 2013;2:e000250.

16. Gurol ME. Secondary stroke prevention in atrial fibrillation: new insights into an old problem. Stroke 2018;49:1315-1317.

17. Sanna T, Diener HC, Passman RS, Di Lazzaro V, Bernstein RA, Morillo $C A$, et al. Cryptogenic stroke and underlying atrial fibrillation. N Engl J Med 2014;370:2478-2486.

18. Rogers JD, Sanders P, Piorkowski C, Sohail MR, Anand R, Crossen $K_{1}$ et al. In-office insertion of a miniaturized insertable cardiac monitor: results from the Reveal LINO In-Office 2 randomized study. Heart Rhythm 2017;14:218-224.

19. Ziegler PD, Rogers JD, Ferreira SW, Nichols AJ, Richards $M$,

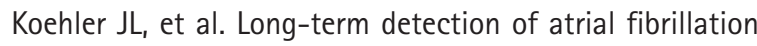
with insertable cardiac monitors in a real-world cryptogenic stroke population. Int J Cardiol 2017;244:175-179.

20. Hart RG, Sharma M, Mundl H, Kasner SE, Bangdiwala SI, Berkowitz SD, et al. Rivaroxaban for stroke prevention after embolic stroke of undetermined source. N Engl J Med 2018 May 16 [Epub]. https://doi.org/10.1056/NEJMoa1802686.

21. Hart RG, Pearce LA, Aguilar MI. Meta-analysis: antithrombotic therapy to prevent stroke in patients who have nonvalvular atrial fibrillation. Ann Intern Med 2007;146:857-867.

22. Aguilar Ml, Hart R, Pearce LA. Oral anticoagulants versus antiplatelet therapy for preventing stroke in patients with non-valvular atrial fibrillation and no history of stroke or transient ischemic attacks. Cochrane Database Syst Rev2007;3:CD006186.

23. Ruff CT, Giugliano RP, Braunwald E, Hoffman EB, Deenadayalu $N$, Ezekowitz MD, et al. Comparison of the efficacy and safety of new oral anticoagulants with warfarin in patients with atrial fibrillation: a meta-analysis of randomised trials. Lancet 2014;383:955-962.

24. Connolly SJ, Ezekowitz MD, Yusuf S, Eikelboom J, Oldgren J, Parekh $A$, et al. Dabigatran versus warfarin in patients with atrial fibrillation. N Engl J Med 2009;361:1139-1151.

25. Patel MR, Mahaffey KW, Garg J, Pan G, Singer DE, Hacke W, et al. Rivaroxaban versus warfarin in nonvalvular atrial fibrillation. N Engl J Med 2011;365:883-891.

26. Granger CB, Alexander JH, McMurray JJ, Lopes RD, Hylek EM, Hanna $M$, et al. Apixaban versus warfarin in patients with atrial fibrillation. N Engl J Med 2011;365:981-992.

27. Giugliano RP, Ruff CT, Braunwald E, Murphy SA, Wiviott SD,

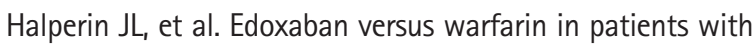
atrial fibrillation. N Engl J Med 2013;369:2093-2104.

28. Pollack CV Jr, Reilly PA, van Ryn J, Eikelboom JW, Glund S, Bernstein $\mathrm{RA}$, et al. Idarucizumab for dabigatran reversal: full cohort analysis. N Engl J Med 2017;377:431-441.

29. Connolly SJ, Milling TJ Jr, Eikelboom JW, Gibson CM, Curnutte JT, Gold A, et al. Andexanet Alfa for acute major bleeding associated with factor Xa inhibitors. N Engl J Med 2016;375: 1131-1141.

30. Nielsen PB, Skjøth F, Søgaard M, Kjældgaard JN, Lip GY, Larsen TB. Effectiveness and safety of reduced dose non-vitamin $\mathrm{K}$ antagonist oral anticoagulants and warfarin in patients with atrial fibrillation: propensity weighted nationwide cohort study. BMJ 2017;356:j510.

31. Tawfik A, Bielecki JM, Krahn M, Dorian P, Hoch JS, Boon H, et al. Systematic review and network meta-analysis of stroke prevention treatments in patients with atrial fibrillation. Clin Pharmacol 2016;8:93-107.

32. Blackshear JL, Odell JA. Appendage obliteration to reduce stroke in cardiac surgical patients with atrial fibrillation. Ann Thorac Surg 1996;61:755-759. 
33. Di Biase $L$, Santangeli $P$, Anselmino M, Mohanty $P$, Salvetti I, Gili $S$, et al. Does the left atrial appendage morphology correlate with the risk of stroke in patients with atrial fibrillation? Results from a multicenter study. J Am Coll Cardiol 2012;60:531-538.

34. Reddy VY, Sievert H, Halperin J, Doshi SK, Buchbinder M, Neuzil $P$, et al. Percutaneous left atrial appendage closure vs warfarin for atrial fibrillation: a randomized clinical trial. JAMA 2014;312:1988-1998.

35. Holmes DR Jr, Kar S, Price MJ, Whisenant B, Sievert H, Doshi SK, et al. Prospective randomized evaluation of the Watchman Left Atrial Appendage Closure device in patients with atrial fibrillation versus long-term warfarin therapy: the PREVAIL trial. J Am Coll Cardiol 2014;64:1-12.

36. Reddy VY, Gibson DN, Kar S, O'Neill W, Doshi SK, Horton RP, et al. Post-approval U.S. experience with left atrial appendage closure for stroke prevention in atrial fibrillation. J Am Coll Cardiol 2017;69:253-261.

37. Tzikas A, Shakir S, Gafoor S, Omran H, Berti S, Santoro G, et al. Left atrial appendage occlusion for stroke prevention in atrial fibrillation: multicentre experience with the AMPLATZER Cardiac Plug. Eurolntervention 2016;11:1170-1179.

38. Bartus K, Morelli RL, Szczepanski W, Kapelak B, Sadowski J, Lee RJ. Anatomic analysis of the left atrial appendage after closure with the LARIAT device. Circ Arrhythm Electrophysiol 2014;7:764-767.

39. Ailawadi G, Gerdisch MW, Harvey RL, Hooker RL, Damiano RJ Jr, Salamon T, et al. Exclusion of the left atrial appendage with a novel device: early results of a multicenter trial. $J$ Thorac Cardiovasc Surg 2011;142:1002-1009.

40. Furlan AJ, Reisman M, Massaro J, Mauri L, Adams H, Albers $\mathrm{GW}$, et al. Closure or medical therapy for cryptogenic stroke with patent foramen ovale. N Engl J Med 2012;366:991-999.

41. Meier B, Kalesan B, Mattle HP, Khattab AA, Hildick-Smith D, Dudek $D$, et al. Percutaneous closure of patent foramen ovale in cryptogenic embolism. N Engl J Med 2013;368:1083-1091.

42. Hagen PT, Scholz DG, Edwards WD. Incidence and size of patent foramen ovale during the first 10 decades of life: an autopsy study of 965 normal hearts. Mayo Clin Proc 1984;59: 17-20.

43. Kerut EK, Norfleet WT, Plotnick GD, Giles TD. Patent foramen ovale: a review of associated conditions and the impact of physiological size. J Am Coll Cardiol 2001;38:613-623.

44. Tobe J, Bogiatzi C, Munoz C, Tamayo A, Spence JD. Transcranial Doppler is complementary to echocardiography for detection and risk stratification of patent foramen ovale. Can J Cardiol 2016;32:986.

45. Evers $\mathrm{S}$, Altenmüller $\mathrm{E}_{1}$ Ringelstein $\mathrm{EB}$. Cerebrovascular isch- emic events in wind instrument players. Neurology 2000;55: 865-867.

46. Cramer SC, Rordorf G, Maki JH, Kramer LA, Grotta JC, Burgin WS, et al. Increased pelvic vein thrombi in cryptogenic stroke: results of the Paradoxical Emboli from Large Veins in Ischemic Stroke (PELVIS) study. Stroke 2004;35:46-50.

47. Wells PS, Ihaddadene R, Reilly A, Forgie MA. Diagnosis of venous thromboembolism: 20 years of progress. Ann Intern Med 2018;168:131-140.

48. Connors JM. Thrombophilia testing and venous thrombosis. N Engl J Med 2017;377:1177-1187.

49. Isayev Y, Chan RK, Pullicino PM. "Economy class" stroke syndrome? Neurology 2002;58:960-961.

50. Homma S, Sacco RL, Di Tullio MR, Sciacca RR, Mohr JP; PFO in Cryptogenic Stroke Study (PICSS) Investigators. Effect of medical treatment in stroke patients with patent foramen ovale: patent foramen ovale in Cryptogenic Stroke Study. Circulation 2002;105:2625-2631.

51. Ntaios G, Papavasileiou V, Sagris D, Makaritsis K, Vemmos K, Steiner $T$, et al. Closure of patent foramen ovale versus medical therapy in patients with cryptogenic stroke or transient ischemic attack: updated systematic review and meta-analysis. Stroke 2018;49:412-418.

52. Niu $X$, Ou-Yang G, Yan PF, Huang SL, Zhang ZT, Zhang ZH. Closure of patent foramen ovale for cryptogenic stroke patients: an updated systematic review and meta-analysis of randomized trials. J Neurol 2018 Jan 30 [Epub]. https://doi. org/10.1007/s00415-018-8766-2.

53. Ando $T$, Holmes AA, Pahuja $M$, Javed $A$, Briasoulis A, Telila $T$, et al. Meta-analysis comparing patent foramen ovale closure versus medical therapy to prevent recurrent cryptogenic stroke. Am J Cardiol 2018;121:649-655.

54. Powers WJ, Rabinstein AA, Ackerson T, Adeoye OM, Bambakidis NC, Becker K, et al. 2018 Guidelines for the early management of patients with acute ischemic stroke: a guideline for healthcare professionals from the American Heart Association/American Stroke Association. Stroke 2018;49:e46-e110.

55. Dellborg M, Eriksson P. Randomized trials of closure of persistent foramen ovale (PFO) vs medical therapy for patients with cryptogenic stroke: effect of lost-to-follow-up and withdrawal of consent. Int J Cardiol 2016;207:308-309.

56. Martín F, Sánchez PL, Doherty E, Colon-Hernandez PJ, Delgado $G$, Inglessis I, et al. Percutaneous transcatheter closure of patent foramen ovale in patients with paradoxical embolism. Circulation 2002;106:1121-1126.

57. Holland TL, Baddour LM, Bayer AS, Hoen B, Miro JM, Fowler VG Jr. Infective endocarditis. Nat Rev Dis Primers 2016;2: 
16059.

58. Habib G, Lancellotti P, Antunes MJ, Bongiorni MG, Casalta JP, Del Zotti F, et al. 2015 ESC guidelines for the management of infective endocarditis: the task force for the management of infective endocarditis of the European Society of Cardiology (ESC). Endorsed by: European Association for Cardio-Thoracic Surgery (EACTS), the European Association of Nuclear Medicine (EANM). Eur Heart J 2015;36:3075-3128.

59. Champey J, Pavese P, Bouvaist $H$, Kastler $A$, Krainik A, Francois $P$. Value of brain MRI in infective endocarditis: a narrative literature review. Eur J Clin Microbiol Infect Dis 2016;35:159168.

60. Baddour LM, Wilson WR, Bayer AS, Fowler VG Jr, Tleyjeh IM, Rybak MJ, et al. Infective endocarditis in adults: diagnosis, antimicrobial therapy, and management of complications. A scientific statement for healthcare professionals from the American Heart Association. Circulation 2015;132:1435-1486.

61. Chakraborty T, Scharf E, Rabinstein AA, DeSimone D, El Rafei A, Brinjikji W, et al. Utility of brain magnetic resonance imaging in the surgical management of infective endocarditis. $J$ Stroke Cerebrovasc Dis 2017;26:2527-2535.

62. Duval $X$, lung $B$, Klein I, Brochet $E_{1}$ Thabut $G$, Arnoult $F$, et al. Effect of early cerebral magnetic resonance imaging on clinical decisions in infective endocarditis: a prospective study. Ann Intern Med 2010;152:497-504.

63. Singhal AB, Topcuoglu MA, Buonanno FS. Acute ischemic stroke patterns in infective and nonbacterial thrombotic endocarditis: a diffusion-weighted magnetic resonance imaging study. Stroke 2002;33:1267-1273.

64. Brownlee WJ, Anderson NE, Barber PA. Intravenous thrombolysis is unsafe in stroke due to infective endocarditis. Intern Med J 2014;44:195-197.

65. Scharf EL, Chakraborty T, Rabinstein A, Miranpuri AS. Endovascular management of cerebral septic embolism: three recent cases and review of the literature. J Neurointerv Surg 2017:9:463-465.

66. García-Cabrera E, Fernández-Hidalgo N, Almirante B, Ivanova-Georgieva $R$, Noureddine $M$, Plata $A$, et al. Neurological complications of infective endocarditis: risk factors, outcome, and impact of cardiac surgery: a multicenter observational study. Circulation 2013;127:2272-2284.

67. Graff-Radford J, Fugate JE, Klaas J, Flemming KD, Brown RD, Rabinstein AA. Distinguishing clinical and radiological features of non-traumatic convexal subarachnoid hemorrhage. Eur J Neurol 2016;23:839-846.

68. Iung B, Tubiana S, Klein I, Messika-Zeitoun D, Brochet E, Lepage $L_{\text {, et }}$ al. Determinants of cerebral lesions in endocarditis on systematic cerebral magnetic resonance imaging: a pro- spective study. Stroke 2013;44:3056-3062.

69. Cooper HA, Thompson EC, Laureno R, Fuisz A, Mark AS, Lin $M$, et al. Subclinical brain embolization in left-sided infective endocarditis: results from the evaluation by MRI of the brains of patients with left-sided intracardiac solid masses (EMBOLISM) pilot study. Circulation 2009;120:585-591.

70. Okazaki S, Sakaguchi M, Hyun B, Nagano K, Tagaya M, Sakata $Y$, et al. Cerebral microbleeds predict impending intracranial hemorrhage in infective endocarditis. Cerebrovasc Dis 2011;32:483-488.

71. Allen LM, Fowler AM, Walker C, Derdeyn CP, Nguyen BV, Hasso AN, et al. Retrospective review of cerebral mycotic aneurysms in 26 patients: focus on treatment in strongly immunocompromised patients with a brief literature review. AJNR Am J Neuroradiol 2013;34:823-827.

72. Ducruet $A F$, Hickman $Z L$, Zacharia BE, Narula R, Grobelny $B T$, Gorski J, et al. Intracranial infectious aneurysms: a comprehensive review. Neurosurg Rev 2010;33:37-46.

73. Yoon NK, McNally S, Taussky P, Park MS. Imaging of cerebral aneurysms: a clinical perspective. Neurovasc Imaging 2016;2: 1-7.

74. Kannoth S, Thomas SV. Intracranial microbial aneurysm (infectious aneurysm): current options for diagnosis and management. Neurocrit Care 2009;11:120-129.

75. Kannoth S, Thomas SV, Nair S, Sarma PS. Proposed diagnostic criteria for intracranial infectious aneurysms. J Neurol Neurosurg Psychiatry 2008;79:943-946.

76. Kim W, Kim EJ. Heart failure as a risk factor for stroke. $J$ Stroke 2018;20:33-45.

77. Abdul-Rahim AH, Perez AC, Fulton RL, Jhund PS, Latini R, Tognoni $\mathrm{G}$, et al. Risk of stroke in chronic heart failure patients without atrial fibrillation: analysis of the Controlled Rosuvastatin in Multinational Trial Heart Failure (CORONA) and the Gruppo Italiano per lo Studio della Sopravvivenza nell'Insufficienza Cardiaca-Heart Failure (GISSI-HF) trials. Circulation 2015;131:1486-1494.

78. Homma S, Thompson JL, Pullicino PM, Levin B, Freudenberger $\mathrm{RS}$, Teerlink JR, et al. Warfarin and aspirin in patients with heart failure and sinus rhythm. N Engl J Med 2012;366:18591869.

79. Cook JL, Colvin M, Francis GS, Grady KL, Hoffman TM, Jessup $M$, et al. Recommendations for the use of mechanical circulatory support: ambulatory and community patient care. A scientific statement from the American Heart Association. Circulation 2017;135:e1145-e1158.

80. Mehra MR, Naka Y, Uriel N, Goldstein DJ, Cleveland JC Jr, Colombo PC, et al. A fully magnetically levitated circulatory pump for advanced heart failure. N Engl J Med 2017;376:440- 
450.

81. Cannegieter SC, Rosendaal FR, Briët E. Thromboembolic and bleeding complications in patients with mechanical heart valve prostheses. Circulation 1994;89:635-641.

82. Murthy SB, Gupta A, Merkler AE, Navi BB, Mandava P, ladecola $C$, et al. Restarting anticoagulant therapy after intracranial hemorrhage: a systematic review and meta-analysis. Stroke 2017;48:1594-1600.

83. Snipelisky D, Kusumoto F. Current strategies to minimize the bleeding risk of warfarin. J Blood Med 2013;4:89-99.

84. Heneghan CJ, Garcia-Alamino JM, Spencer EA, Ward AM,

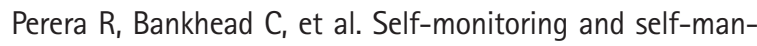
agement of oral anticoagulation. Cochrane Database Syst Rev 2016;7:CD003839.

85. Kajermo U, Ulvenstam A, Modica A, Jernberg T, Mooe T. Incidence, trends, and predictors of ischemic stroke 30 days after an acute myocardial infarction. Stroke 2014:45:1324-1330.

86. Hachet O, Guenancia C, Stamboul K, Daubail B, Richard C, Béjot $Y$, et al. Frequency and predictors of stroke after acute myocardial infarction: specific aspects of in-hospital and postdischarge events. Stroke 2014;45:3514-3520.

87. Levine GN, Bates ER, Bittl JA, Brindis RG, Finn SD, Fleisher LA, et al. 2016 ACC/AHA guideline focused update on duration of dual antiplatelet therapy in patients with coronary artery disease: a report of the American College of Cardiology/ American Heart Association Task Force on Clinical Practice Guidelines. J Am Coll Cardio/ 2016;68:1082-1115.

88. Gibson CM, Mehran R, Bode C, Halperin J, Verheugt FW, Wildgoose $P$, et al. Prevention of bleeding in patients with atrial fibrillation undergoing PCI. N Engl J Med 2016;375:2423-2434.

89. Cannon CP, Bhatt DL, Oldgren J, Lip GYH, Ellis SG, Kimura T, et al. Dual antithrombotic therapy with dabigatran after $\mathrm{PCl}$ in atrial fibrillation. N Engl J Med 2017;377:1513-1524.

90. Eikelboom JW, Connolly SJ, Bosch J, Dagenais GR, Hart RG, Shestakovska 0, et al. Rivaroxaban with or without aspirin in stable cardiovascular disease. N Engl J Med 2017;377:13191330. 